\title{
Dimensionality and Determinants of Self-Reported Cognitive Failures
}

\author{
Dimensionalidad y determinantes de las fallas cognitivas autoinformadas
}

William C. Tirre ${ }^{1}$

\begin{abstract}
This research examined the dimensionality and the correlates of self-reported cognitive failures. The first goal was to determine what factors, in addition to a general one, are needed to explain self-reported cognitive failures. To explore this issue, both Rasch measurement and confirmatory factor analysis were employed. The second goal was to determine if cognitive failures might be predicted with personality factors, general cognitive ability, and the need for cognition. A sample of 552 USAF airmen responded to the Broadbent Cognitive Failures Questionnaire (CFQ), a Big-Five personality inventory, the Abstract Reasoning Test, the Speeded Cognitive Ability Test, and the Need for Cognition survey. Both Rasch modeling and confirmatory factor analysis indicated that a single factor dominated CFQ responses. Regression analysis showed that CFQ responses were predicted well by personality factors $(R=.60)$.

\section{Resumen}

Esta investigación examinó la dimensionalidad y los determinantes de las fallas cognitivas autoinformadas. El primer objetivo fue determinar qué factores podrían ser necesarios para explicar los fallos cognitivos autoinformados. Para llevar a cabo esto, se emplearon tanto la medición de Rasch como el análisis factorial confirmatorio. El segundo objetivo, era determinar si las fallas cognitivas podrían predecirse a partir de factores de personalidad, la capacidad cognitiva general y la necesidad de cognición. Una muestra de 552 aviadores de la Fuerza Aérea de los Estados Unidos de América (USAF), respondió al Cuestionario de Fallas Cognitivas Broadbent (CFQ), el cuestionario Big-Five de personalidad, la Prueba de Razonamiento Abstracto, la Prueba de Habilidad Cognitiva Acelerada, y la Encuesta de Necesidad de Cognición. Tanto el modelo de Rasch como el análisis factorial confirmatorio indicaron que un solo factor agrupaba las respuestas de CFQ. El análisis de regresión mostró que las respuestas de CFQ se pronosticaron bien por factores de personalidad $(R=.60)$.
\end{abstract}

\section{Keywords:}

Cognitive failures, personality factors, cognitive ability.

Palabras Claves:

Fallas cognitivas, factores de personalidad, capacidad cognitiva.

1. National Center for Education Statistics, Institute for Education Sciences, U.S. Department of Education. 550 12th Street, S.W., Washington DC 20202. E-mail: william.tirre@ed.gov. This research was conducted at the Air Force Research Laboratory, where the author was previously employed. E-mail: william.tirre@ed.gov.

Manuscript received 25-08-2017; revised 7-12-2017; accepted 14-12-2017.

\section{Introduction}

Cognitive failures are "absent-minded" errors that occur in simple tasks. Norman, (1981) posited three major types - errors in the formation of intentions, faulty activation of schemata, and false triggering of actions. The consequences of cognitive failures can be serious, including automobile and aircraft accidents (Larson,
Alderton, Neideffer, \& Underhill, 1997; Reason, 1977, 1979), unintentional shoplifting (Reason \& Lucas, 1984), and industrial accidents (Hassanzadeh-Rangi, Farshad, Khosravi, Zare, \& Mirkazemi, 2014).

Because enlisted personnel in the United States Air Force engage in a variety of occupations in which cognitive failures can be disastrous (e.g., aircraft maintenance, air traffic and combat control, munitions 
maintenance, and airborne cryptologic language analysis, to mention just a few of the 200-plus Air Force occupations), the Air Force Research Laboratory was interested in understanding the structure and determinants of cognitive failures.

The incidence of cognitive failures has been related to various factors: boredom, worry, divided attention (Robertson, Manly, Andrade, Baddeley, \& Yiend, 1997), working memory overload, diminished attention and vigilance levels, and incidental learning (Broadbent, Cooper, FitzGerald, \& Parkes, 1982; Pollina, Greene, Tunick, \& Puckett, 1992). Personality correlates of cognitive failures include social consciousness and social anxiety (Houston, 1989). A fairly comprehensive review of the cognitive failures literature including the effects of situational factors, transient psychological states, and neurological variables is available from Carrigan \& Barkus (2016).

In recent years research has emerged on mindwandering, a construct conceptually related to cognitive failures. The cognitive mechanisms involved in the phenomenon of mind-wandering are the subject of some debate (McVay \& Kane, 2009, 2010; Smallwood, 2010). However, in a study closer to the concerns of the present research, Robison, Gath, and Unsworth (2017) investigated how individual differences in mindwandering were a function of working memory capacity, attentional control, and neuroticism. In neuroticism the person experiences unwanted thoughts that intrude on task focus. The results of their correlational study showed that persons scoring high on neuroticism reported more mind-wandering during cognitive tasks, showed lower working memory capacity, and poorer attention control. In another study, Kane et al. (2007) found that in cognitive tasks placing high demands on concentration, high working memory capacity individuals were better at maintaining on-task thoughts and engaged in less mind-wandering than were lower working memory capacity individuals. These findings were consistent with theories of working memory that emphasize the role of executive attention and control processes in determining individual differences in cognitive performance.

Other research in this paradigm has suggested that mind-wandering is not necessarily negative. For example, Baird, Smallwood, and Schooler (2011) found that when persons with greater working memory capacity let their minds wander, they often engage in thoughts about the future. This evidence suggests that using spare capacity to think productively (e.g. planning the next action) during relatively simple tasks reflects a cognitive system that is adaptively functioning (Smallwood \& Andrews-Hanna, 2013). But this issue is far from settled. Robison and Unsworth (2017) conducted a study that failed to replicate the finding that working memory capacity is positively related to future-oriented off-task thought.
Another construct that is conceptually related to cognitive failures is mindfulness, which is defined as "the state of being attentive to and aware of what is taking place in the present ... and can be considered an enhanced attention to and awareness of current experience or present reality" (Brown \& Ryan, 2003, p. 822). Klockner and Hicks (2015) found a correlation of -.73 between a self-report measure of cognitive failures and the Mindful Attention Awareness Scale (MAAS). Also, of the five personality factors they included in their study only neuroticism (or anxiety) was correlated with cognitive failures $(r=.52)$.

Mrazek, Franklin, Phillips, Baird, and Schooler (2013) reported an experiment that examined whether a training course on mindfulness would decrease mind wandering and improve performance on working memory and academic achievement tests. Mindfulness training improved both GRE reading comprehension scores and working memory capacity. Also noted were reductions in the occurrence of distracting thoughts while responding to the GRE and the working memory test.

Mindfulness as defined by Brown and Ryan (2003) appears to be tapping a construct similar in some respects to the need for cognition, which has been defined as "a need to structure relevant situations in meaningful, integrated ways" and "a need to understand and make reasonable the experiential world" (Cohen, Stotland, \& Wolfe, 1955, p. 291). More recently, Cacioppo and Petty (1982) defined the need for cognition as an individual's tendency to "engage in and enjoy thinking" (p. 116) and the tendency to "organize, abstract, and evaluate information" (p. 124). They also defined the construct as a stable propensity to engage in and intrinsically enjoy effortful cognitive work (Cacioppo, Petty, Feinstein, \& Jarvis, 1996; Thompson, Chaiken, \& Hazelwood, 1993).

With regards to the relationship between the need for cognition and the propensity for cognitive failures, if the need for cognition is positively related to mindfulness, then the correlation between the need for cognition and cognitive failures would be negative. If instead a high need for cognition is characteristic of pensive individuals who get lost in their thoughts (or let their minds wander) and make distracted errors, then the correlation would be positive. No study relating the need for cognition to cognitive failures has been found in the published literature.

\section{The Dimensionality of the Cognitive Failures Questionnaire}

The majority of the published research on cognitive failures has involved self-report questionnaires often using an instrument devised by Broadbent, Cooper, FitzGerald, \& Parkes (1982). Broadbent et al. (1982) developed the Cognitive Failures Questionnaire (CFQ) to measure the propensity to have lapses in three areas: perception, memory, and motor function. It 
was expected that a general factor of cognitive failures would suffice. But factor analyses of the CFQ suggested a more complex model. In the research literature there are reports of two and seven factor models (Matthews, Coyle, \& Craig, 1990), five factors (Pollina et al., 1992), four factors (Wallace, Kass, \& Stanny, 2002), and three factors (Larson et al., 1997). These previous analyses were all in the exploratory mode with either principal factors or components.

Most recently Bridger, Johnsen, and Brasher (2013) reported a confirmatory factor analysis of the CFQ in which a five-factor model was fit to the data resulting in a comparative fit index (CFI) of .87, and a root mean square of approximation (RMSEA) of .07, neither of which indicate a good model fit. A single factor model was only marginally worse: $\mathrm{CFI}=.84$, RMSEA $=.07$. But Bridger et al. (2013) found that Cronbach's alpha was .92, which is evidence of high internal consistency for a unidimensional construct. These investigators also reported a test-retest reliability of .71 over two years, which suggests a human characteristic that is fairly stable over time.

In the present study confirmatory factor analysis was used to test a nested hierarchical model, a type of structural model that has been used in the cognitive abilities domain (e.g., Chaiken, Kyllonen, \& Tirre, 2000; Gustafsson \& Balke, 1993; Tirre \& Field, 2002; Tirre \& Raouf, 1998). In the nested hierarchical model a general factor is posited which underlies all items, and various group factors are posited for smaller sets of items. The group factors are orthogonal to the general factor and to each other. Thus, a nested hierarchical model attempts to reconcile a multiple correlated group factor model with a general factor model, by positing a general factor that loads all variables and various orthogonal group factors which load smaller sets of variables. Rasch measurement analysis (Rasch, 1960/1980; Wright \& Stone, 1979) was also employed as an alternative method to investigate dimensionality.

\section{Determinants of Cognitive Failures}

It was suspected that even if cognitive failures primarily reflected a unitary dimension, it was possible that there were multiple paths leading to errors of this nature. The studies reviewed suggest various factors of individual differences that could be hypothesized as determinants of cognitive failures. Included here are working memory/attention and general cognitive ability, need for cognition/mindfulness, and the personality factors of anxiety, conscientiousness, and intellect. Thus, there are four hypotheses that can be posited:

H1: Cognitive failures reflect individual differences in general cognitive ability such that persons who have less cognitive ability are more prone to cognitive failures. As tests of general cognitive ability place high demands on working memory
(Kyllonen \& Christal, 1990; Carpenter, Just, \& Shell, 1990), this hypothesis is related to the overloaded working memory hypothesis (e.g., Robison, Gath, \& Unsworth, 2017). Two types of general cognitive ability measures were employed. The Speeded Cognitive Abilities Test is an example of a heterogeneous measure of intelligence (or general cognitive ability) (Gustafsson, 1994) which attempts to tap the common variance among a diverse set of cognitive items. The StanfordBinet might be the first historical example of this type of intelligence measure. The Abstract Reasoning test is an example of a homogeneous measure of intelligence (Gustafsson, 1994) which attempts to tap the core processes of cognitive ability like eduction of relations and correlates with a narrowly specified set of items. The Ravens Progressive Matrices test is an early example of this type of intelligence measure. Two types of general cognitive ability tests were included in the predictor set so that the construct could be more adequately measured.

H2: The second hypothesis is actually two opposing hypotheses. H2a posits that cognitive failures are positively correlated with the need for cognition (or intellect/openness), because pensive, reflective individuals might be expected to be more prone to absentminded mistakes. In contrast, $\mathrm{H} 2 \mathrm{~b}$ posits that individuals with a high need for cognition (i.e., a need to engage in cognitively demanding tasks) are more mindful of situations as they unfold and can avoid careless mistakes. The Big Five personality factor intellect (openness) is conceptually related to need for cognition and was included in the predictor set because at least one study reported a negative correlation between intellect and incidence of cognitive failures (Di Fabio, 2006).

H3: The third hypothesis is that highly anxious persons are more prone to cognitive failures because worry and emotionality direct attention away from other cognitive processes (Broadbent, Broadbent, \& Jones, 1986; Derakshan \& Eysenck, 2009; Klockner \& Hicks, 2015; Robison et al., 2017; Sarason, 1988; Wine, 1971).

H4: It is hypothesized that conscientiousness is negatively associated with self-reported cognitive failures. Conscientious people are typically selfdisciplined, emotionally stable, hardworking, and achievement-oriented. They adhere to social norms, engage in goal-directed behavior, take responsibility, keep organized, and avoid risk-taking. Highly conscientious people are hypothesized to expend extra effort to avoid cognitive failures, hence a negative correlation is predicted. Klockner and Hicks (2015) did not find a correlation between workplace errors and 
conscientiousness; but this relationship might vary across populations and work contexts.

These hypotheses were tested using multiple regression with scores on a general factor derived from the Broadbent Cognitive Failures Questionnaire as the dependent variable.

\section{Method}

\section{Participants}

The sample for the analysis of the Cognitive Failures Questionnaire was composed of 992 USAF airmen in basic training. Eighty-two percent of the sample was male, with a mean age of 19.8 years with a range of 17 to 31 . The demographic breakdown was $68 \%$ (in USAF population: 61\%) white, 15\% (23\%) black, 9\% (10\%) Hispanic, 7\% (6\%) Asian and other racial groups. In terms of education, .5\% did not have a high school diploma or General Education Diploma (GED), 1.6\% had a GED, 57\% had a high school diploma, 36\% had some college, $3 \%$ had an associate's degree, $1.6 \%$ had a bachelor's degree, and .3\% had some graduate work. For the entire battery of tests, 552 cases had complete data after listwise deletion.

\section{Instruments}

Three psychological questionnaires and two cognitive ability tests were administered:

1. Cognitive Failures Questionnaire (Broadbent et al., 1982) -- a self-report measure of the relative frequency of various types of "minor mistakes" made in the past six months. A five point scale was used $(0$ $=$ Never, $1=$ Very rarely, $2=$ Occasionally, $3=$ Quite often, 4 = Very often). There were 25 items.

2. Need for Cognition (Cacioppo \& Petty, 1982) -- This test consisted of 46 items about the respondent's mental habits and preferences for deep thinking and problem solving. Each statement was rated on a five-point Likert scale: Strongly Disagree, Disagree, Neutral, Agree, Strongly Agree.

3. Self-Descriptive Inventory (Christal, 1993; Collis \& Barucky, 1999) -- a measure of the Big Five Personality factors (Digman, 1990), viz., Openness (or Intellect), Conscientiousness, Extraversion, Agreeableness, and Neuroticism (or Anxiety).
There were 164 items asking the respondents to indicate how often a descriptive phrase or word applies to them (Always, Usually, Often, Sometimes, Rarely, Never).

4. Speeded Cognitive Ability Test (SCAT) -- a 20 minute speeded intelligence test modeled after the Wonderlic Personnel Test with a variety of item types involving verbal, spatial, and quantitative content.

5. Abstract Reasoning Test (Embretson, 1998) -- a nonverbal figural reasoning test of 20 items based on the Raven's Progressive Matrices test. Each item presented a $3 \times 3$ array of figures, with one position blank to be filled in by one of eight options that completed the pattern by some logical rule.

\section{Procedure}

Paper-and-pencil tests were administered in two counterbalanced orders to groups of 40 respondents in classrooms.

\section{Results}

\section{Dimensionality of the CFQ}

One way to test the dimensionality of the CFQ is to submit the item response data to Rasch model analysis. The key statistics from this analysis were the Person Separation Reliability $=.909$ and the Person Separation Index $=3.16$ (which indicates that about five strata were distinguishable in the measure). Only two items (7 \& 10) did not fit the Rasch model well according to the Mean Square Infit $(1.39,1.38)$ and the Mean Square Outfit $(1.39,1.36)$ criteria. Overall, the Rasch analysis indicated that one dimension appeared to underlie the measure.

A second way to test the dimensionality of the CFQ was confirmatory factor analysis via EQS (Bentler, 2006) which indicated that a multifactorial, viz., a nested hierarchical model, provided an advantage in goodness of fit (see Table 1). However, this analysis also indicated that the general factor was very strong, accounting for $70.5 \%$ of the common variance. The five group factors loaded only three items apiece and accounted for a smaller percentage of the observed variance, $29.5 \%$, with values ranging from 2.95 to 7.57 percent for the individual factors. 
Table 1

Confirmatory factor analysis of broadbent cognitive failures questionnaire

\begin{tabular}{|c|c|c|c|c|c|c|c|}
\hline Item & $\begin{array}{l}\text { General } \\
\text { Cognitive } \\
\text { Failure }\end{array}$ & $\begin{array}{l}\text { Forget } \\
\text { Names }\end{array}$ & $\begin{array}{l}\text { Forget } \\
\text { Turns }\end{array}$ & $\begin{array}{l}\text { Failure to } \\
\text { Comprehend } \\
\text { Reading }\end{array}$ & $\begin{array}{l}\text { Lose } \\
\text { Temper }\end{array}$ & $\begin{array}{l}\text { Confuse } \\
\text { Left \& Right }\end{array}$ & Communality \\
\hline BCF01 & 0.429 & & & 0.903 & & & 0.999 \\
\hline BCF02 & 0.592 & & & 0.189 & & & 0.386 \\
\hline BCF03 & 0.588 & & & & & 0.189 & 0.381 \\
\hline BCF04 & 0.513 & & & & & 0.858 & 0.999 \\
\hline BCF05 & 0.536 & & & & & 0.159 & 0.313 \\
\hline BCF06 & 0.635 & & & & & & 0.403 \\
\hline BCF07 & 0.450 & 0.460 & & & & & 0.414 \\
\hline BCF08 & 0.562 & & & & 0.173 & & 0.346 \\
\hline BCF09 & 0.543 & 0.119 & & & & & 0.309 \\
\hline BCF10 & 0.450 & & & & 0.520 & & 0.473 \\
\hline BCF11 & 0.490 & & 0.192 & & & & 0.277 \\
\hline BCF12 & 0.528 & & 0.849 & & & & 1.000 \\
\hline BCF13 & 0.665 & & & & -0.207 & & 0.485 \\
\hline BCF14 & 0.550 & & & & & & 0.303 \\
\hline BCF15 & 0.588 & & & & & & 0.346 \\
\hline BCF16 & 0.597 & & & & & & 0.356 \\
\hline BCF17 & 0.644 & & & & & & 0.415 \\
\hline BCF18 & 0.630 & & 0.157 & & & & 0.422 \\
\hline BCF19 & 0.604 & & & 0.170 & & & 0.394 \\
\hline BCF20 & 0.518 & 0.634 & & & & & 0.670 \\
\hline BCF21 & 0.676 & & & & & & 0.457 \\
\hline BCF22 & 0.645 & & & & & & 0.416 \\
\hline BCF23 & 0.674 & & & & & & 0.454 \\
\hline BCF24 & 0.555 & & & & & & 0.308 \\
\hline BCF25 & 0.546 & & & & & & 0.298 \\
\hline Sums of Squares: & 8.194 & 0.628 & 0.782 & 0.880 & 0.343 & 0.797 & 11.624 \\
\hline$\%$ of Variance: & 70.489 & 5.400 & 6.730 & 7.571 & 2.952 & 6.858 & \\
\hline Goodness of Fit: & df & chi-square & $\mathrm{p}$ & chi-square/df & CFI & RMSEA & \\
\hline Single Factor: & 275 & $1,336.47$ & $<.001$ & 4.86 & 0.876 & 0.062 & \\
\hline Six Factor: & 260 & 879.42 & $<.002$ & 3.38 & 0.927 & 0.049 & \\
\hline
\end{tabular}

Note: $\mathrm{df}=$ degrees of freedom, $\mathrm{CFI}=$ comparative fit index, RMSEA= root mean square of approximation.

Chi-square difference $=457.05$, degrees of freedom $=15, p<.0001$.

The data for the CFQ were also analyzed with the SPSS Factor program which can provide factor scores. A principal axes factor analysis with a Quartimax rotation was run and factor scores were computed. The Quartimax rotation was chosen because it provides a solution in which the first factor is essentially a general factor, and it and the remaining narrower factors are orthogonal to each other. As it turns out, the factor loadings for the first factor for the Quartimax solution were correlated $\mathrm{r}=.995$ with those from the general factor resulting from the nested hierarchal solution obtained from EQS. Thus, the general factor score for the $\mathrm{CFQ}\left(\mathrm{G}_{\mathrm{CFQ}}\right)$ was selected as the dependent variable for subsequent analysis.

\section{Descriptive statistics and correlates of the CFQ}

The descriptive statistics for all variables are presented in Table 2. 
Table 2

Descriptive statistics for all variables

\begin{tabular}{llll}
\hline Variable & Mean & SD & Reliability* \\
\hline Cognitive Failures & 0.065 & .976 & .92 \\
Abstract Reasoning & 12.795 & 4.808 & .87 \\
SCAT & 30.797 & 6.775 & .87 \\
Intellect & 0.015 & .997 & .92 \\
Conscientious & -0.005 & .989 & .94 \\
Extraversion & 0.021 & .977 & .94 \\
Agreeableness & -0.011 & .989 & .95 \\
Anxiety & -0.041 & .976 & .95 \\
Need for Cognition & 0.017 & .996 & .93 \\
\hline
\end{tabular}

Note. $\mathrm{N}=552$. All variables except abstract reasoning and speeded cognitive ability test are factor scores.

*All reliability estimates were Cronbach's alpha, except for the speeded cognitive ability test which was a split-half reliability.

\section{Regression model of the CFQ}

Zero order correlations among the variables (Table 3 ) indicated that all variables other than the SCAT score were significantly related to cognitive failures. The strongest correlates of cognitive failures were anxiety $(r=.45)$, need for cognition $(r=-.41)$, and conscientiousness $(r=-.37)$.

A regression model in which the general factor for the $\mathrm{CFQ}\left(\mathrm{G}_{\mathrm{CFQ}}\right)$ was regressed on the five personality variables, need for cognition, and the two cognitive ability variables explained 36.5 percent of the criterion variance (Table 4). The strongest prediction in terms of standardized regression coefficients were by need for cognition (beta $=-.332$ ), anxiety (beta $=.302$ ), and conscientiousness (beta $=-.263$ ). Other significant predictors were intellect (beta $=.193$ ), and abstract reasoning (beta $=-.131$ ).

Table 3

Correlations among all variables

\begin{tabular}{|c|c|c|c|c|c|c|c|c|c|}
\hline & CF & NFC & INT & SCAT & AR & $A G$ & ANX & EXT & CONS \\
\hline Cognitive Failures (CF) & 1.000 & & & & & & & & \\
\hline Need for Cognition (NFC) & -0.413 & 1.000 & & & & & & & \\
\hline Intellect (INT) & -0.084 & 0.606 & 1.000 & & & & & & \\
\hline SCAT & -0.050 & 0.188 & 0.120 & 1.000 & & & & & \\
\hline Abstract Reasoning (AR) & -0.129 & 0.183 & 0.134 & 0.458 & 1.000 & & & & \\
\hline Agreeableness (AG) & -0.182 & 0.250 & 0.193 & -0.064 & -0.023 & 1.000 & & & \\
\hline Anxiety (ANX) & 0.452 & -0.344 & -0.028 & -0.149 & -0.068 & -0.155 & 1.000 & & \\
\hline Extraversion (EXT) & -0.130 & 0.238 & 0.139 & -0.001 & -0.012 & 0.147 & -0.164 & 1.000 & \\
\hline Conscientious (CONS) & -0.374 & 0.343 & 0.237 & -0.076 & -0.090 & 0.361 & -0.180 & 0.204 & 1.000 \\
\hline
\end{tabular}

Note. $N=552$. Critical $r$ for $p<.05$ is .0834 .

Table 4

Regression equation for predicting cognitive failures

\begin{tabular}{|c|c|c|c|c|c|c|c|}
\hline & \multicolumn{2}{|c|}{ Unstandardized Coefficients } & \multirow{2}{*}{$\frac{\text { Standardized Coefficients }}{\text { Beta }}$} & \multirow[b]{2}{*}{$\mathrm{t}$} & \multirow[b]{2}{*}{$\mathrm{p}$} & \multicolumn{2}{|c|}{ Correlations } \\
\hline & B & Std. Error & & & & Zero-order & Partial \\
\hline (Constant) & .090 & .163 & & .552 & .581 & & \\
\hline Need for Cognition & -.325 & .048 & -.332 & -6.725 & .000 & -.413 & -.277 \\
\hline Intellect & .189 & .044 & .193 & 4.339 & .000 & -.084 & .183 \\
\hline SCAT & .011 & .006 & .074 & 1.876 & .061 & -.050 & .080 \\
\hline Abstract Reasoning & -.027 & .008 & -.131 & -3.351 & .001 & -.129 & -.142 \\
\hline Agreeableness & .003 & .037 & .003 & .081 & .935 & -.182 & .003 \\
\hline Anxiety & .302 & .038 & .302 & 7.917 & .000 & .452 & .322 \\
\hline Extraversion & .023 & .036 & .023 & .644 & .520 & -.130 & .028 \\
\hline Conscientious & -.260 & .039 & -.263 & -6.748 & .000 & -.374 & -.278 \\
\hline
\end{tabular}

Note. $\mathrm{R}$-square $=.365, \mathrm{~F}(8,543)=39.05, \mathrm{p}<.0001$ 
Note that need for cognition and intellect, which are correlated at about $r=.6$, and are both negatively correlated with cognitive failures, had regression coefficients opposite in sign. The negative relationship (either zero order correlation or regression coefficient) found for need for cognition was the opposite of what was predicted. This finding and the positive regression weight for intellect indicated the need for an analysis of how these variables combine in relation to cognitive failures. A similar situation was noted for abstract reasoning and the speeded cognitive ability test, which were positively correlated $(r=.46)$ to each other, and negatively related to cognitive failures, but had regression coefficients opposite in sign (beta $=-.132$ and $.074 \mathrm{~ns}$, respectively).

In situations like this with strongly correlated predictors, one approach is to create composite variables. In this case, an intellect/need for cognition composite was created; and a g (general cognitive ability) composite was created from abstract reasoning and the speeded cognitive ability test. The multiple regression with these composites replacing their component variables explained 30.8 percent of the variance (down from 36.5 percent); and the regression coefficients were reduced in absolute value (beta: -.100 for composite vs. -.332 for need for cognition and .193 for intellect; -.074 for composite vs. -.131 for abstract reasoning and .074 for SCAT).

A second approach is to simply eliminate the variable in each pair that manifests less correlation with the dependent variable. In this case, that meant eliminating intellect and the SCAT Personnel Test. The resulting percentage of variance explained fell to 33.9 from 36.5 and the regression coefficients were reduced (beta: -.198 vs. -..332 for need for cognition, -.091 vs. -.131 for abstract reasoning).

The pattern of relationships among the dependent variable, the need for cognition, and intellect, and among the dependent variable, abstract reasoning, and the speeded cognitive ability test exemplify suppression effects (Cohen, Cohen, West, \& Aiken, 2003). A suppressor variable is substantially correlated with another predictor but is weakly correlated with the dependent variable. The variance the suppressor shares with the other predictor is irrelevant to the dependent variable. Thus, when a suppressor variable is included in the regression equation, unwanted variance in the predictor is removed or "suppressed" and the regression weight for the predictor increases. It appears that intellect and the Speed Cognitive Ability Test were suppressor variables and their coefficients will not be given a substantive interpretation.

\section{Discussion}

The evidence obtained from this study and its predecessors in the literature suggest that cognitive failures as measured by Broadbent's questionnaire are multidimensional with a dominating general factor. There is also evidence, albeit limited to one study, that there is some stability to the measure over time. This fact suggests that one can think of cognitive failures as a characteristic propensity of the individual to make absent-minded errors, have lapses of attention, to forget what task one is supposed to be doing etc. The exact degree to which it is generalizable across situations is at this point still unknown. This research question might be approached through a faceted test design and application of generalizability theory (G-theory, Shavelson \& Webb, 1991). G-theory estimates variance in scores based on each person, each facet, and their combination (interactions). If facets (e.g., situations and types of cognitive failures) are small sources of error variance, then one can be more confident that cognitive failures are generalizable and characteristic of people.

One limitation of this study is that both the dependent variable (cognitive failures) and most of the predictor variables were measured through selfreporting. The validity of self-report measures can be compromised by social desirability, though there are measures of this type of response bias (Paulhus, 1991) for statistical mitigation of this threat to validity. It would be preferable to have a performance test in which the construct of cognitive failures could be measured objectively. An example might be a driving simulation with multiple intermittent situations requiring operator attentiveness to avoid an accident (Gugerty \& Tirre, 2000). The drawback with performance tests is that they tend to be domain specific (which works against generalizability) and because cognitive failures are intermittent, a good measure would require several hours of testing. A self-report rating scale such as Broadbent's Cognitive Failures Questionnaire (CFQ) remains a viable and practical choice for the study of cognitive failure as a predictor variable.

In the present study, the CFQ was used as a dependent variable because the goal was to understand its dimensionality and its correlates in the personality and cognitive domains. Evidence from both Rasch model analysis and confirmatory factor analysis indicated that a general factor explained about 71 percent of the variance. Five narrow factors loading three items each were also identified, which together accounted for about 29 percent of the variance.

Most of the hypothesized relationships were confirmed by the analysis. People who report making relatively frequent but usually minor cognitive mistakes tend to be higher in anxiety and lower in conscientiousness, suggesting that their attention might be divided between their immediate cognitive tasks and their internal psychological states, perhaps including worries and ruminations. Frequent cognitive failures might also appear in people who are less disciplined and orderly in their behaviors (signaling low conscientiousness). 
Interestingly, a high need for cognition was negatively associated with cognitive failures, which was consistent with hypothesis $\mathrm{H} 2 \mathrm{~b}$, not positively as in hypothesis H2a. Thus, the person who enjoys complex ideas and abstractions is not someone who is so lost in his thoughts that he makes absent-minded mistakes. Instead, persons with a high need for cognition tend to operate well in the "here and now" and avoid this type of mistake. There is also a modest positive correlation between need for cognition and the general cognitive ability measures used in this study, which is to be expected. Recall that abstract reasoning was also negatively associated with cognitive failures; but ability as measured by the speeded cognitive ability test was not significantly related.

Another limitation of this study was that participants were young people about 20 years of age on average. Age might interact with cognitive ability or personality factors in influencing cognitive failures and this study cannot address such hypotheses.

There is much to be learned about how seemingly minor cognitive mistakes can occur. The evidence acquired in this study indicates that certain stable attributes of the person in the personality and ability domains might indicate a propensity for these mistakes. But much of the systematic variance in cognitive failures remains unexplained, and it could be that task and situational demands and their interaction with individual attributes will explain much of the residual variance. Future research on cognitive failures might benefit from a carefully constructed instrument that goes beyond the original definition offered by Broadbent et al. (1982) which focused on memory problems and action slips. The definition might be expanded to incorporate other types of common everyday failures such as errors occurring during problem solving, distractibility, and mind-wandering (Carrigan \& Barkus, 2016). A faceted design for a questionnaire might use multiple varieties of cognitive failures as one facet and perhaps situation or context as another, making it possible to better test the dimensionality and the generalizability of the construct.

\section{Acknowledgements}

William C. Tirre is now at the National Center for Education Statistics, Institute for Education Sciences, U.S. Department of Education.

This research was conducted as part of the Learning Abilities Measurement Program, work unit 2313-T1-33, funded by the Air Force Office of Scientific Research. The author acknowledges the contributions of Janice Hereford, who designed the page layouts for the questionnaires and prepared the data files for analysis. The opinions expressed in this article are the author's alone, and do not represent the opinions of the Air Force Research Laboratory.

\section{References}

Baird, B., Smallwood, J., \& Schooler, J. W. (2011). Back to the future: autobiographical planning and the functionality of mind-wandering. Consciousness and cognition, 20(4), 1604-1611.

Bentler, P. M. (2006). EQS 6 Structural Equations. Encino, CA: Multivariate Software, Inc.

Bridger, R. S., Johnsen, S. A., \& Brasher, K. (2013). Psychometric properties of the Cognitive Failures Questionnaire. Ergonomics, 56(10), 1515-1524. doi:https://doi.org/10.1080/00140139.2013.8 21172

Broadbent, D. E., Broadbent, M. H., \& Jones, J. L. (1986). Performance correlates of self-reported cognitive failure and of obsessionality. British Journal of Clinical Psychology, 25(4), 285-299.

Broadbent, D. E., Cooper, P. F., FitzGerald, P., \& Parkes, K. R. (1982). The cognitive failures questionnaire (CFQ) and its correlates. British journal of clinical psychology, 21(1), 1-16.

Brown, K., \& Ryan, R. M. (2003). The benefits of being present: Mindfulness and its role in psychological well-being. Journal of Personality and Social Psychology, 84(4), 822- 848.

Cacioppo, J. T., \& Petty, R. E. (1982). The need for cognition. Journal of Personality and Social Psychology, 42, 116-131.

Cacioppo, J. T., Petty, R. E., Feinstein, J. A., \& Jarvis, W. B. (1996). Dispositional differences in cognitive motivation: The life and times of individuals varying in need for cognition. Psychological bulletin, 119(2), 197-253.

Carpenter, P. A., Just, M. A., \& Shell, P. (1990). What one intelligence test measures: a theoretical account of the processing in the Raven Progressive Matrices Test. Psychological review, 97(3), 404-431.

Carrigan, N., \& Barkus, E. (2016). A systematic review of cognitive failures in daily life: healthy populations. Neuroscience and Biobehavioral Reviews, 63, 29-42.

Chaiken, S. R., Kyllonen, P. C., \& Tirre, W. (2000). Organization and components of psychomotor ability. Cognitive Psychology, 40(3), 198-226.

Christal, R. E. (1993). R\&D Summary report F3361591-D-0010. Armstrong Laboratories, Brooks AFB.

Cohen, A. R., Stotland, E., \& Wolfe, D. M. (1955). An experimental investigation of need for cognition. The Journal of Abnormal and Social Psychology, 51(2), 291-294. doi:http://dx.doi.org/10.1037/ h0042761

Cohen, J., Cohen, P., West, S. G., \& Aiken, L. S. (2003). Applied Multiple Regression/Correlation Analysis for the Behavioral Sciences (3ra ed.). Mahwah, New Jersey: Lawrence Eribaum Associates. Inc. 
Collis, J. M., \& Barucky, J. M. (1999). "Big Five" Personality Factors Research Using Christal's Self Description Inventory. Metrica Inc. Bryan, TX.

Derakshan, N., \& Eysenck, M. W. (2009). Anxiety, processing efficiency, and cognitive performance: New developments from attentional control theory. European Psychologist, 14(2), 168-176.

Di Fabio, A. (2006). Decisional procrastination correlates: personality traits, self-esteem or perception of cognitive failure? International Journal for Educational and Vocational Guidance, 6(2), 109-122.

Digman, J. M. (1990). Personality structure: Emergence of the five-factor model. Annual review of psychology, 41(1), 417-440.

Embretson, S. E. (1998). A cognitive design system approach to generating valid tests: Application to abstract reasoning. Psychological Methods, 3(3), 380-396. doi:http://dx.doi. org/10.1037/1082-989X.3.3.380

Gugerty, L. J., \& Tirre, W. C. (2000). Individual differences in situation awareness. In M. R. Endsley, \& D. J. Garland (Edits.), Situation Awareness Analysis and Measurement (págs. 249-276). Mahwah, NJ: Lawrence Erlbaum Associates.

Gustafsson , J. E. (1994). General intelligence. In R. J. Sternberg (Ed.), Encyclopedia of Human Intelligence (págs. 469-474). NY: Macmillian Publishing Company.

Gustafsson , J. E., \& Balke , G. (1993). General and Specific Abilities as Predictors of School Achievement. Multivariate Behavioral Research, 28(4), 407-434. doi:https://doi.org/10.1207/ s15327906mbr2804 2

Hassanzadeh-Rangi, N., Farshad, A. A., Khosravi, Y., Zare, G., \& Mirkazemi, R. (2014). Occupational cognitive failure and its relationship with unsafe behaviors and accidents. International journal of occupational safety and ergonomics, 20(2), 265-271.

Houston, D. M. (1989). The relationship between cognitive failure and self-focused attention. British Journal of Clinical Psychology, 28(1), 85-86.

Kane, M. J., Brown, L. H., McVay, J. C., Silvia, P. J., Myin-Germeys, I., \& Kwapil, T. R. (2007). For whom the mind wanders, and when: An experience-sampling study of working memory and executive control in daily life. Psychological science, 18(7), 614-621.

Klockner, K., \& Hicks, R. E. (2015). Cognitive failures at work, mindfulness, and the Big Five. GSTF Journal of Psychology (JPsych), 2(1), 1-7.

Kyllonen, P. C., \& Christal, R. E. (1990). Reasoning ability is (little more than) working-memory capacity?! Intelligence, 14(4), 389-433.
Larson, G. E., Alderton, D. L., Neideffer, M., \& Underhill, E. (1997). Further evidence on dimensionality and correlates of the Cognitive Failures Questionnaire. British Journal of Psychology, 88(1), 29-38.

Matthews, G., Coyle, K., \& Craig, A. (1990). Multiple factors of cognitive failure and their relationships with stress vulnerability. Journal of Psychopathology and Behavioral Assessment, 12(1), 49-65.

McVay, J. C., \& Kane, M. J. (2009). Conducting the train of thought: Working memory capacity, goal neglect, and mind wandering in an executivecontrol task. Journal of Experimental Psychology: Learning, Memory, and Cognition, 35(1), 196-204.

McVay, J. C., \& Kane, M. J. (2010). Does mind wandering reflect executive function or executive failure? Comment on Smallwood and Schooler (2006) and Watkins (2008). Psychological Bulletin, 136(2), 188-197. doi:http://dx.doi. org/10.1037/a0018298

Mrazek, M. D., Franklin, M. S., Phillips, D. T., Baird, B., \& Schooler, J. W. (2013). Mindfulness training improves working memory capacity and GRE performance while reducing mind wandering. Psychological science, 24(5), 776-781.

Norman, D. A. (1981). Categorization of action slips. Psychological Review, 88(1), 1-15. doi:http:// dx.doi.org/10.1037/0033-295X.88.1.1

Paulhus, D. L. (1991). Measurement and control of response bias. In J. P. Robinson, P. R. Shaver, \& L. S. Wrightsman, Measures of social psychological attitudes. Vol. 1. Measures of personality and social psychological attitudes (págs. 17-59). San Diego: Academic Press. doi:http://dx.doi.org/10.1016/ B978-0-12-590241-0.50006-X

Pollina, L. K., Greene, A. L., Tunick, R. H., \& Puckett, J. M. (1992). Dimensions of everyday memory in young adulthood. British Journal of Psychology, 83(3), 305-321.

Rasch, G. (1960/1980). Probabilistic models for some intelligence and attainment tests (Expanded Edition, Chicago, University of Chicago Press). Copenhagen: Danish Institute for Educational Research.

Reason, J. T. (1977). Skill and error in everyday life. In M. Howe (Ed.), Adult learning (págs. 21-45). London: Wiley.

Reason, J. T. (1979). Actions not as planned: The price of automation. In G. Underwood, \& R. Stevens (Edits.), Aspects of consciousness (págs. 67-89). London: Academic Press.

Reason, J. T., \& Lucas, D. (1984). Absent-mindedness in shops: Its incidence, correlates and consequences. British Journal of Clinical Psychology, 23(2), 121-131. 
Robertson, I. H., Manlya, T., Andradea, J., Baddeleya, B. T., \& Yienda, J. (1997). 'Oops!': Performance correlates of everyday attentional failures in traumatic brain injured and normal subjects. Neuropsychologia, 35(6), 747-758. doi:https:// doi.org/10.1016/S0028-3932(97)00015-8

Robison, M. K., \& Unsworth, N. (2017). Working memory capacity and mind-wandering during low-demand cognitive tasks. Consciousness and Cognition, 52, 47-54.

Robison, M. K., Gath, K. I., \& Unsworth, N. (2017). The neurotic wandering mind: An individual differences investigation of neuroticism, mind-wandering, and executive control. The Quarterly Journal of Experimental Psychology, 70(4), 649-663. doi:https:// doi.org/10.1080/17470218.2016.1145706

Sarason, I. G. (1988). Anxiety, self-preoccupation and attention.Anxiety Research, 1(1), 3-7.doi:https:// doi.org/10.1080/10615808808248215

Shavelson, R. J. \& Webb, N. M. (1991). Generalizability theory: A primer. Newbury Park, CA: Sage.

Smallwood, J. (2010). Why the global availability of mind wandering necessitates resource competition: Reply to McVay and Kane (2010). Psychological Bulletin, 136(2), 202-207. doi:http://dx.doi.org/10.1037/a0018673

Smallwood, J., \& Andrews-Hanna, J. (2013). Not all minds that wander are lost: the importance of a balanced perspective on the mind-wandering state. Frontiers in Psychology, 4(441), 1-6.

Thompson, E. P., Chaiken, S., \& Hazlewood, J. D. (1993). Need for cognition and desire for control as moderators of extrinsic reward effects: A person $\times$ situation approach to the study of intrinsic motivation. Journal of Personality and Social Psychology, 64(6), 987-999. doi:http:// dx.doi.org/10.1037/0022-3514.64.6.987

Tirre, W. C., \& Field, K. A. (2002). Structural models of abilities measured by the ball aptitude battery. Educational and Psychological Measurement, 62(5), 830-856. doi:https://doi. org/10.1177/001316402236881

Tirre, W. C., \& Raouf, K. K. (1998). Structural models of cognitive and perceptual-motor abilities. Personality andIndividualDifferences, 24(5),603-614.doi:https:// doi.org/10.1016/S0191-8869(98)80011-1

Wallace, J. C., Kass, S. J., \& Stanny, C. J. (2002). The cognitive failures questionnaire revisited: Dimensions and correlates. The Journal of General Psychology, 129(3), 238-256. doi:https://doi. org/10.1080/00221300209602098

Wine, J. (1971). Test anxiety and direction of attention. Psychological Bulletin, 76(2), 92-104. doi:http:// dx.doi.org/10.1037/h0031332

Wright, B. D., \& Stone, M. H. (1979). Best Test Design. Rasch Measurement. Chicago, IL: MESA Press. 